\title{
Relative normalized luciferase activity for the recombinant vector constructs carrying the ancestral and variant alleles for XRCC2:rs3218550 and PHB:rs6917
}

\author{
Nirmala Dushyanthi Sirisena ${ }^{1^{*}} \mathbb{D}$, Nilakshi Samaranayake² and Vajira H. W. Dissanayake ${ }^{1}$
}

\begin{abstract}
Objective: The data presented herein represents the preliminary results of the functional assays of a recently conducted larger study in which two single nucleotide polymorphisms (SNPs) [XRCC2:rs3218550 and PHB:rs6917] were significantly associated with risk of breast cancer among Sri Lankan postmenopausal women. The rs3218550 T allele and rs6917 A allele were found to increase breast cancer risk by 1.5-fold and 1.4-fold, respectively. Both SNPS are located in the $3^{\prime}$ untranslated region (3'UTR) of the respective genes. It was hypothesized that these non-coding SNPs may be exerting some transcriptional regulatory effects on gene expression. Their putative functional effects were further investigated by generating bioluminescent recombinant experimental reporter gene constructs carrying the ancestral and variant alleles of these 2 SNPs, transiently transfecting them in MCF-7 breast cancer cell lines and performing dual-luciferase reporter gene assays to measure the luminescent signals.

Data description: The normalized relative luciferase activity for the recombinant vector constructs carrying the ancestral and variant alleles for XRCC2:rs3218550 and PHB:rs6917 are presented herein. This data might be of relevance to other researchers involved in delineating the functional mechanisms of SNPs located in the $3^{\prime}$ UTR of the XRCC2 and PHB breast cancer related genes.
\end{abstract}

Keywords: Alleles, Breast cancer, Luciferase activity, Reporter genes, Single nucleotide polymorphisms, Vectors

\section{Objective}

Herein we present the preliminary functional assay data of a recently published larger case-control study, involving 350 Sri Lankan postmenopausal women with histologically confirmed invasive breast cancer (cases), and 350 healthy postmenopausal women (controls), in which common genetic polymorphisms in the XRCC2 and $P H B$ genes were associated with increased risk of sporadic breast cancer [1]. Another paper describing the genetic variants associated with the clinicopathological profiles in this cohort was also recently published [2].

\footnotetext{
*Correspondence: nirmala@anat.cmb.ac.lk

${ }^{1}$ Human Genetics Unit, Faculty of Medicine, University of Colombo, No. 25 Kynsey Road, Colombo 8, Sri Lanka

Full list of author information is available at the end of the article
}

Two single nucleotide polymorphisms (SNPs) [rs32 18550:NC_000007.14:g.152646870C $>\mathrm{T}, \quad \mathrm{X}$-ray repair cross-complementing gene-2 (XRCC2)/7q36.1; and rs6 917:NC_000017.11:g.49404181G>A, prohibitin-1 gene $(P H B) / 17 \mathrm{q} 21.33]$ showed the strongest evidence for association with breast cancer risk. The rs3218550 $\mathrm{T}$ allele and rs6917 A allele were found to breast cancer risk by 1.5-fold and 1.4-fold, respectively.

Both are non-coding SNPs located in the 3 'untranslated region ( $\left.3^{\prime} \mathrm{UTR}\right)$. The exact biological mechanisms by which they regulate breast cancer risk is unclear $[3,4]$. Polymorphisms in the $3^{\prime}$ UTR have been reported to be associated with various phenotypic effects due to their regulatory actions on gene and protein expression [5].

We hypothesized that these two SNPs may exert transcriptional regulatory effects. Their putative functional 
effects were investigated by generating recombinant experimental reporter gene constructs carrying the ancestral and variant alleles of each SNP, transfecting them in MCF-7 breast cancer cell lines and performing the dual-luciferase reporter gene assay to measure luminescent signals. Bioluminescent reporter genes provide an efficient method for the indirect measurement of relative rates of transcription. We believe the data generated might be of relevance to other researchers involved in delineating the functional mechanisms of SNPs located in the $3^{\prime} \mathrm{UTR}$ of the XRCC2 and $P H B$ breast cancer related genes.

\section{Data description}

The data files 1 and 2 shown in Table 1 represent the normalized relative luciferase activity for the recombinant experimental vector constructs carrying the ancestral and variant alleles for XRCC2:rs3218550 and PHB:rs6917 SNPs, respectively [6]. The results are expressed as relative luminescence units (RLU) and the ratio between firefly luciferase/renilla luciferase provide the normalized luciferase activity for each vector. The normalized luciferase activity for the two control vectors, pGL3P vector lacking the insert (experimental empty vector) and the pGL3C vector containing the SV40 promoter and enhancer, are also given for each experiment. The triplicate results indicated for each vector represent the data obtained from three independent transfections of MCF-7 breast cancer cell lines and dual-luciferase assays performed under similar experimental conditions.

The recombinant experimental reporter gene constructs carrying the 116 bp $3^{\prime}$ UTR insert of $X R C C 2$ :rs3218550 and 148bp $3^{\prime}$ UTR insert of PHB:rs6917 were generated using the Gateway recombination cloning technology with Clonase II (ThermoFisher Scientific, USA). Samples which were previously identified as homozygous for the ancestral and variant alleles of rs3218550 and rs6917 were used as the PCR templates for the production of the inserts. The Gateway pDONR $^{\mathrm{TM}} 221$ donor vector and the $\mathrm{pGL3P3}{ }^{\prime} \mathrm{GW}$ destination vector were used. Data file 3 shows the sequences of the $3^{\prime} U T R$ vector constructs, primer sequences and vector diagrams.

Transient transfection of the recombinant experimental reporter gene constructs into cultured MCF-7 breast cancer cells (ECACC catalogue no. 86012803) was carried out using FuGENE HD transfection reagent (Promega, USA). Cells were plated at a density of $2 \times 10^{5}$ in 12 -well culture plates in complete medium and cultured for $24 \mathrm{~h}$ to attain $50-70 \%$ confluency before transfection. Each transfection experiment was carried out with the recombinant experimental vectors carrying the two alleles of rs3218550 and rs6916. In parallel, the pGL3P and pGL3C vectors (Promega, USA) were also transfected in each experiment. All vectors were co-transfected with the internal control vector (pRL-SV40) for normalisation purpose.

The transfection mixture for each well consisted of 1ug of experimental vector DNA and $10 \mathrm{ng}$ pRL-SV40 vector along with FuGENE HD:vector DNA at a ratio of 3:1 in 50 ul complete medium, based on the optimized FuGENE HD protocol database (Promega, USA). The cultured MCF-7 cells were allowed to express the transfected DNA for $24 \mathrm{~h}$. Dual-luciferase reporter assay (Promega, USA) was performed following passive lysis of the transfected cells. All luminescent signals were measured using the Glomax 20/20 Luminometer with dual auto injector system (Promega, USA).

\section{Limitations}

- The small size of the datasets obtained in this study prevented the data from being used as part of a full research paper.

- The variability observed among the replicates could probably be due to variations in the amounts of reporter genes which may have entered into the cultured cells during the three independent transient transfection assays. In addition, as most transcription factors are present at low concentrations, only a small proportion of reporters entering the cell may receive the full complement of proteins needed for the proper functioning of the regulatory region under

Table 1 Overview of data files

\begin{tabular}{llll}
\hline Label & Name of data file & $\begin{array}{l}\text { File types } \\
\text { (file extension) }\end{array}$ & $\begin{array}{l}\text { Data repository and identifier (Dol or accession } \\
\text { number) }\end{array}$ \\
\hline Data file 1 & $\begin{array}{l}\text { Relative luciferase activity for the recombinant vector } \\
\text { constructs carrying C and T alleles for rs3218550 }\end{array}$ & MS Excel file (.xlsx) & Figshare [https://doi.org/10.6084/m9.figshare.6854189] [6] \\
Data file 2 & $\begin{array}{l}\text { Relative luciferase activity for the recombinant vector } \\
\text { constructs carrying G and A alleles for rs6917 }\end{array}$ & MS Excel file (.xlsx) & Figshare [https://doi.org/10.6084/m9.figshare.6854189] [6] \\
Data file 3 $\begin{array}{l}\text { Sequences of 3'UTR inserts, primer sequences, partial } \\
\text { electropherograms of final experimental vectors and } \\
\text { vector diagrams }\end{array}$ & MS Word file (.docx) & Figshare [https://doi.org/10.6084/m9.figshare.6854189] [6] \\
\hline
\end{tabular}


study. Such limitations are intrinsic to reporter gene assays.

- Transient recombinant experimental reporter genes are not always an appropriate assay to assess the influence of small differences due to SNP variation on the transcriptional activity of a particular gene, partly due to the lack of an appropriate chromatin confirmation.

- The functional assays were designed to check the regulatory effects of the individual SNPs and not the effect of haplotypes.

- The experiments were not replicated with change in variables such as cell line being used and the type of promoters present in the vectors to fully explore the potential regulatory effects.

\section{Abbreviations}

3'UTR: 3'untranslated region; PHB: prohibitin-1; SNP: single nucleotide polymorphisms; XRCC2: X-ray repair cross-complementing gene- 2 .

\section{Authors' contributions}

VHWD conceived the study. NDS was the PhD student who under the supervision of VHWD and NS designed the current study, carried it out and drafted the manuscript. Both supervisors made equal contributions to the study. All authors critically reviewed and revised the manuscript for important intellectual content. All authors read and approved the final manuscript.

\section{Author details}

${ }^{1}$ Human Genetics Unit, Faculty of Medicine, University of Colombo, No. 25 Kynsey Road, Colombo 8, Sri Lanka. ${ }^{2}$ Department of Parasitology, Faculty of Medicine, University of Colombo, Colombo 8, Sri Lanka.

\section{Acknowledgements}

Not applicable.

\section{Competing interests}

The authors declare that they have no competing interests.

\section{Availability of data materials}

The datasets generated and/or analyzed during the current study are available in the Figshare repository [https://doi.org/10.6084/m9.figshare.6854189] [6].

\section{Ethics approval and consent to participate}

Written, informed consent from all study participants and ethical clearance to conduct this study was obtained from the Ethics Review Committee, Faculty of Medicine, University of Colombo [EC-15-082].

\section{Funding}

This research was supported by a PhD scholarship awarded to NDS from the University of Colombo [AP/3/2/2015/PG/07] and the University Grants Commission, Sri Lanka [UGC/DRIC/PG/2015(i)/CMB/01]. The funding bodies did not play any role in the study design, collection, analysis, and interpretation of data and in writing the manuscript.

\section{Publisher's Note}

Springer Nature remains neutral with regard to jurisdictional claims in published maps and institutional affiliations.

Received: 8 August 2018 Accepted: 31 August 2018

Published online: 04 September 2018

\section{References}

1. Sirisena ND, Adeyemo A, Kuruppu Al, Neththikumara N, Samaranayake N, Dissanayake VHW. Genetic determinants of sporadic breast cancer in Sri Lankan women. BMC Cancer. 2018;18:180.

2. Sirisena ND, Adeyemo A, Kuruppu Al, Samaranayake N, Dissanayake VHW. Genetic variants associated with clinicopathological profiles in sporadic breast cancer in Sri Lankan women. J Breast Cancer. 2018;21:165-72.

3. Jiao L, Hassan MM, Bondy ML, Wolff RA, Evans DB, Abbruzzese $J L$, et al. $X R C C 2$ and XRCC3 gene polymorphism and risk of pancreatic cancer. Am J Gastroenterol. 2008:103:360-7.

4. Leal MF, Cirilo PDR, Mazzotti TKF, Calcagno DQ, Wisnieski F, Demachki S, et al. Prohibitin expression deregulation in gastric cancer is associated with the 3'untranslated region $1630 \mathrm{C}>$ T polymorphism and copy number variation. PLoS ONE. 2014;9:e98583. https://doi.org/10.1371/journ al.pone.0098583.

5. Jia YM, Xie YT, Wang YJ, Han JY, Tian XX, Fang WG. Association of genetic polymorphisms in CDH1 and CTNNB1 with breast cancer susceptibility and patients' prognosis among Chinese Han women. PLOS ONE. 2015;10:e0135865. https://doi.org/10.1371/journal.pone.0135865.

6. Nirmala Dushyanthi Sirisena, Nilakshi Samaranayake, Vajira H.W. Dissanayake. Relative normalized luciferase activity for the recombinant vector constructs carrying the ancestral and variant alleles for XRCC2:rs3218550 and PHB:rs6917 datasets. Figshare 2018. https://doi.org/10.6084/m9.figsh are.6854189.

\section{Consent for publication}

Not applicable.

Ready to submit your research? Choose BMC and benefit from:

- fast, convenient online submission

- thorough peer review by experienced researchers in your field

- rapid publication on acceptance

- support for research data, including large and complex data types

- gold Open Access which fosters wider collaboration and increased citations

- maximum visibility for your research: over 100M website views per year

At BMC, research is always in progress.

Learn more biomedcentral.com/submissions 